\title{
Improving the solubility of nevirapine using A hydrotropy and mixed hydrotropy based solid dispersion approach
}

\author{
Jyotsana R. Madan ${ }^{1, A-F}$, Virendra J. Kamate ${ }^{1, A-F}$, Kamal Dua ${ }^{2,3,4, A, C-F}$, Rajendra Awasthi, ${ }^{5, A, C-F}$ \\ ${ }^{1}$ Department of Pharmaceutics, Sinhgad Technical Education Society's, Smt. Kashibai Navale College of Pharmacy, Pune, Maharashtra, India \\ ${ }^{2}$ Discipline of Pharmacy, Graduate School of Health, University of Technology Sydney, Sydney, Australia \\ ${ }^{3}$ School of Pharmacy and Biomedical Sciences, The University of Newcastle, Newcastle, Australia \\ ${ }^{4}$ School of Pharmaceutical Sciences, Shoolini University, Solan, India \\ ${ }^{5}$ NKBR College of Pharmacy \& Research Centre, Meerut, India \\ A - research concept and design; $\mathrm{B}$ - collection and/or assembly of data; $\mathrm{C}$ - data analysis and interpretation; \\ $D$ - writing the article; $E$ - critical revision of the article; $F$ - final approval of the article
}

Polymers in Medicine, ISSN 0370-0747 (print), ISSN 2451-2699 (online)

Polim Med. 2017:47(2):83-90

Address for correspondence

Jyotsana R. Madan

E-mail: jyotsna.madan@sinhgad.edu

\section{Funding sources \\ none declared}

Conflict of interest

none declared

Received on June 15, 2017

Reviewed on July 4, 2017

Accepted on September 19, 2017

\begin{abstract}
Background. Nevirapine, an antiviral drug, is a potent reverse transcriptase inhibitor (NNRTI). It is used in combination with nucleoside analogues for treatment of HIV type-1 (HIV-1) infection and AIDS. Nevirapine is a BCS class II drug which shows dissolution rate limited absorption.

Objectives. The aim of the present research was to provide a fast dissolving solid dispersion of nevirapine.

Material and methods. The solubility of nevirapine was initially determined individually in four hydrotropic agents - namely urea, lactose, citric acid and mannitol - at a concentration of 10, 20, 30 and $40 \% \mathrm{w} / \mathrm{v}$ solutions using purified water as a solvent. The highest solubility was obtained in the $40 \%$ citric acid solution. Then different combinations of 2 and 3 hydrotropic agents in different ratios were used to determine solubility, so that the total concentration of hydrotropic agents was always $40 \%$.
\end{abstract}

Results. The highest solubility was obtained in a solution of lactose and citric acid at the optimum ratio of 15:25. This optimized combination was utilized in preparing solid dispersions by a common solvent technique using distilled water as a solvent. The solid dispersions were evaluated for XRD, DSC and FTIR to show no drug-hydrotrope interaction.

Conclusions. It was concluded that the concept of mixed hydrotropic solid dispersion is a safe, novel and cost-effective technique for enhancing the bioavailability of poorly water-soluble drugs by dissolving the drug in a nonionized form. The enhancement in solubility of nevirapine using hydrotropy is a clear indication of its potential to be used in the future for other poorly water-soluble drugs in which low bioavailability is a major concern.

Key words: nevirapine, solid dispersion, mixed hydrotropy
DOI

10.17219/pim/77093

Copyright

○ 2017 by Wroclaw Medical University

This is an article distributed under the terms of the Creative Commons Attribution Non-Commercial License (http://creativecommons.org/licenses/by-nc-nd/4.0/) 
One of the important phenomena in pharmaceutical formulation is "solubility", which plays very effective and significant role in the formulation of various dosage forms. ${ }^{1,2}$ The solubility of a compound in a particular solvent is defined as the concentration of a solute in a saturated solution at a certain temperature. ${ }^{3,4}$ The solubility of a drug molecule may be a critical factor determining its usefulness since the solubility dictates the amount of compound that will dissolve and therefore the amount available for absorption. If a compound has low water solubility, it may be subject to dissolution rate limited absorption within the gastrointestinal residence time. ${ }^{5,6}$ The term "hydrotrope" was introduced by Neuberg in 1916. A hydrotropic agent is a compound that solubilizes hydrophobic compounds in aqueous solutions. Hydrotropy is a molecular phenomenon whereby the adding of a large amount of a second solute (hydrotrope) results to an increase in the aqueous solubility of poorly soluble solutes. ${ }^{7,8}$ Hydrotropes possess a hydrophobic as well as a hydrophilic group. The hydrophobic part is too small to cause spontaneous self-aggregation. The efficiency of a hydrotropic agent depends on the balance between hydrophobic and hydrophilic parts of the hydrotrope. Finding the right hydrotropic agent for a certain poorly soluble drug necessitates a screening of numerous hydrotropic agents based on the balance between hydrophobic and hydrophilic parts. The presence of a large hydrophobic part leads to better hydrotropic efficiency. ${ }^{9}$ The enhancement of aqueous solubility by a hydrotropic agent is based on 1) molecular self-association of the hydrotropic agent and 2) the association of hydrotrope molecules with the solute. ${ }^{10}$ Mixed hydrotropic solubilization has great potential to improve the solubility of poorly water soluble molecules. ${ }^{11-13}$

Nevirapine (NVP), an antiviral drug, is a potent reverse transcriptase inhibitor (NNRTI). It is used in combination with nucleoside analogues for the treatment of HIV type-1 (HIV-1) infection and AIDS. It is a BCS class II drug with high permeability and low solubility (aqueous solubility $0.09941 \mathrm{mg} / \mathrm{mL}) .{ }^{14,15}$ The solubility of NVP was increased by using a mixed hydrotropic solid dispersion technique. Here, two or more hydrotropic blends were used, which gives a synergistic solubility enhancement effect on poorly water soluble drugs. The individual concentrations of hydrotropic agents are reduced, thus minimizing the probability of their toxicity. ${ }^{16,17}$
The aim of this research was to enhance the solubility of NVP in water by making use of hydrotropes and their combination blends to prepare its solid dispersion.

\section{Material and methods}

\section{Material}

The NVP was gifted by Wockhardt Ltd., Aurangabad, India. Urea, sodium benzoate, citric acid, lactose and mannitol were purchased from Loba Chem Pvt. Ltd., Mumbai, India. All reagents were of analytical grade and used as received.

\section{Methods}

\section{Determination of solubility}

The saturation solubility of NVP was determined with distilled water. An excess amount of NVP was added to each medium and kept in an incubator shaker at $200 \mathrm{rpm}$ for $24 \mathrm{~h}$. The temperature was maintained at $37^{\circ} \mathrm{C}$. After $24 \mathrm{~h}$ the mixture was centrifuged at $2000 \mathrm{rpm}$ for $10 \mathrm{~min}$. The supernatants were diluted using distilled water. The absorbance of samples was measured at $282 \mathrm{~nm}$ for distilled water using a UV spectrophotometer (JASCO V-630, Tsukuba, Japan). ${ }^{18,19}$

\section{NVP-hydrotropic agent interference study}

\section{UV spectrophotometric study}

Interference of the hydrotropic agents was estimated using the UV spectrophotometric method. Briefly, the absorbance of NVP standard solutions were determined in distilled water alone and in the presence of the hydrotropic blend, respectively (Table 1). The absorbance was recorded against respective blank medium at appropriate wavelengths. A UV-visible spectrophotometer (JASCO $\mathrm{V}$-630) with $1 \mathrm{~cm}$ matched silica cells was employed for spectrophotometric estimations. ${ }^{20}$

\section{Fourier-transform infrared spectroscopy (FTIR)}

The FTIR spectral data of NVP, physical mixtures of NVP and individual hydrotropes and NVP with two

Table 1. Results of drug-hydrotrope interference study by UV spectrophotometric method

\begin{tabular}{|l|c|c|c|c|c|}
\hline Drug & Solvent system & Drug conc. $[\mu \mathrm{g} / \mathrm{mL}]$ & Hydrotrope conc. $[\mu \mathrm{g} / \mathrm{mL}]$ & Wavelength $[\mathrm{nm}]$ & Absorbance against blank \\
\hline NVP & dist. water $+P$ & 50 & 1000 & 282 & 0.233 \\
NVP & dist. water $+\mathrm{Q}$ & 50 & 1000 & 282 & 0.256 \\
NVP & dist. water +R & 50 & 1000 & 282 & 0.223 \\
NVP & dist. water $+S$ & 50 & 1000 & 282 & 0.219 \\
NVP & dist. water & 50 & 1000 & 282 & 0.201 \\
\hline
\end{tabular}

P - lactose; Q - urea; R - citric acid; S - mannitol. 
hydrotropes were taken for the determination of possible molecular interaction between the drug and excipients by the $\mathrm{KBr}$ disc method using an FTIR spectrophotometer (Shimadzu Affinity-1, Kyoto, Japan). The samples were scanned over a range $4000-400 \mathrm{~cm}^{-1}{ }^{21}$

\section{Equilibrium solubility studies in different hydrotropic} agents

Initially the equilibrium solubility studies were carried out in different hydrotropic agents. The aqueous hydrotropic solutions of lactose $(\mathrm{P})$, urea $(\mathrm{Q})$, citric acid $(\mathrm{R})$ and mannitol $(\mathrm{S})$ were prepared individually at a concentration of 10, 20, 30 and 40\% w/v. Accurately measured $10 \mathrm{~mL}$ of a particular blend of hydrotropic agent was taken in a $10 \mathrm{~mL}$ vial, and an excess amount of NVP was added and mechanically shaken until a saturated solution was formed. The vial was shaken on a mechanical shaker for $12 \mathrm{~h}$ and the solution was allowed to equilibrate for $24 \mathrm{~h}$ to achieve equilibrium solubility. The resultant solution was centrifuged at $2000 \mathrm{rpm}$ for $10 \mathrm{~min}$ in an ultracentrifuge and further filtered through Whatman grade 41 filters. An aliquot was diluted with distilled water and analyzed using a UV spectrophotometer at $282 \mathrm{~nm} .^{22,23}$ Enhancement ratios in solubility were calculated by the following formula:

$\underset{\text { ratio }}{\text { enhancement }}=\frac{\text { solubility of drug in hydrotropic solution }}{\text { solubity of drug in water }}$.

Similarly, the equilibrium solubility studies were carried out in different blends of hydrotropic agents. Here, the combinations of 2-3 hydrotropic agents were taken at a 1:1 ratio and dissolved in water to get a clear solution. An excess amount of NVP was added to the hydrotropic solution. The saturated solution was mechanically shaken and aqueous solubility was determined. Further, the ratio of the mixed hydrotropic agent was optimized to achieve the highest aqueous solubility of NVP.

\section{Formulation of hydrotropic solid dispersions of NVP}

For the preparation of the hydrotropic solid dispersion (1:4 ratio), accurately weighed 1.5 g lactose and $2.5 \mathrm{~g}$ of citric acid were taken in a $100 \mathrm{~mL}$ beaker and mixed properly. A sufficient quantity of freshly prepared demineralized water $(5 \mathrm{~mL})$ was added to dissolve the hydrotropic mixture. Dissolution of the hydrotropic mixture was facilitated by the agitation of a Teflon coated magnetic rice bead on a high speed magnetic stirrer. After complete dissolution of the hydrotropic mixture, $1 \mathrm{~g}$ of NVP was dissolved in the above solution and the temperature was maintained at $57 \pm 2^{\circ} \mathrm{C}$ to evaporate the water. As evaporation proceeded, the speed of the rice bead automatically decreased and it stopped stirring when most of the water was evaporated, thus indicating the formation of the solid dispersion (wet). The wet solid dispersion was kept in a hot air dry oven maintained at $50 \pm 2^{\circ} \mathrm{C}$ to remove the remaining moisture. After a complete drying, the solid dispersion was crushed using a clean and dry glass mortar and pestle, passed through a \#60 sieve and finally stored in an airtight glass bottle. ${ }^{24-26}$

\section{Evaluation of hydrotropic solid dispersion containing NVP}

\section{Micromeritic properties of solid dispersions}

The prepared hydrotropic solid dispersion was characterized for various micromeritic properties such as bulk density, tapped density, compressibility index, Hausner ratio and angle of repose. ${ }^{27,28}$

For the determination of density, the solid dispersion sample $(1 \mathrm{~g})$ was taken into a $10 \mathrm{~mL}$ graduated measuring cylinder and the initial volume was noted down. The graduated measuring cylinder was tapped 50 times using USP bulk density apparatus (ETD 1020, Electrolab, Mumbai, India). The bulk density and tapped density were determined using the following formula:

bulk density $\left(\mathrm{g} / \mathrm{cm}^{-3}\right)=\frac{\text { weight of the solid dispersion }}{\text { initial volume }}$,

tapped density $\left(\mathrm{g} / \mathrm{cm}^{-3}\right)=\frac{\text { weight of the solid dispersion }}{\text { volume after tapping }}$.

The compressibility index was determined by the following formula:

$$
\underset{\text { index }}{\text { compressibility }}=\frac{\text { tapped density }- \text { bulk density }}{\text { tapped density }} \times 100 \text {. }
$$

The Hausner ratio was determined by the following formula:

$$
\text { Hausner's ratio }=\frac{\text { tapped density }}{\text { bulk density }} .
$$

For the determination of angle of repose, the solid dispersion was poured through a funnel. The funnel was fixed at a position in such a way that its lower tip was at a height of $2 \mathrm{~cm}$ above the surface. The sample was poured till the tip of the particle pile surface touched the funnel. The $\tan ^{-1}$ of the ratio of the height of the pile and radius of its base gave the angle of repose. The angle of repose was determined by the following formula:

$$
\tan ^{-1}=\frac{\mathrm{h}}{\mathrm{r}}
$$




\section{X-ray powder diffraction analysis}

The X-ray diffraction pattern of pure NVP and a physical mixture of the drug and hydrotropic agents (lactose + citric acid) was recorded by X-ray powder diffractometer (Philips 1710). The X-ray diffraction patterns were recorded using $\mathrm{Cu}-\mathrm{Ka}$ radiation $(\lambda=1.5405980 \AA)$, a current of $30 \mathrm{~mA}$ and a voltage of $40 \mathrm{kV}$. The samples were analyzed, over 10-89 2 theta, range with a scan step size of 0.02 and 0.50 s per step. ${ }^{29,30}$

\section{Differential scanning calorimetry analysis}

In order to determine the physical state of the NVP, the differential scanning calorimetry (DSC) thermograms of pure NVP and physical mixture of the drug and hydrotropic agents (lactose + citric acid) was recorded using a differential scanning calorimeter (DSC 4000, PerkinElmer, Waltham, Massachusetts, USA). The instrument was calibrated using indium $\left(156^{\circ} \mathrm{C}\right)$, tin $\left(232^{\circ} \mathrm{C}\right)$ and zinc $\left(419.5^{\circ} \mathrm{C}\right)$ as internal standards. An empty aluminum pan was used as a reference. Each sample was accurately weighed into an aluminum pan and sealed. The probes were heated from 30 to $300^{\circ} \mathrm{C}$ at a rate of $10 \mathrm{~K} / \mathrm{min}$ under a nitrogen atmosphere. ${ }^{31,32}$

\section{Results and discussion}

\section{Determination of solubility}

The solubility of NVP as observed in distilled water was $0.0994 \pm 0.056 \mathrm{mg} / \mathrm{mL}$. The results indicate poor solubility of NVP in distilled water.

\section{NVP hydrotropic agent interference study}

\section{Ultraviolet spectrophotometric study}

To examine the interference of a hydrotropic agent, the UV absorbance spectrum of NVP was recorded in distilled water alone and in the presence of the hydrotropic blend solutions. The results indicated no change in the wavelength of maximum absorbance $\left(\lambda_{\max }\right)$ of NVP in distilled water. Hence, it was concluded that there was no drug-hydrotrope interference.

\section{Fourier-transform infrared study}

Fourier-transform infrared study was employed to examine the possible interactions of NVP and the hydrotropes. The FTIR spectrum of NVP showed characteristic peaks at $3400 \mathrm{~cm}^{-1}$ of $\mathrm{N}-\mathrm{H}$ (secondary amine) stretch, $3190 \mathrm{~cm}^{-1}$ of $\mathrm{C}-\mathrm{H}$ (aromatic) stretch, $3062 \mathrm{~cm}^{-1}$ of $\mathrm{C}-\mathrm{H}$ (aliphatic) stretch, $1647 \mathrm{~cm}^{-1}$ of $\mathrm{C}=\mathrm{O} \mathrm{cm} \mathrm{cm}^{-1}$ (ketone) stretch, $1587-1417 \mathrm{~cm}^{-1}$ of $\mathrm{C}=\mathrm{C}$ stretch and 1296 $\mathrm{cm}^{-1}$ of $\mathrm{C}=\mathrm{O}$ (ketone) bending. All peaks are within the reported range, indicating the purity of NVP. ${ }^{33,34}$ All the major peaks of NVP are also present in the FTIR spectrum of the hydrotropic physical mixture. Hence, there were no drug-excipient interactions (Fig. 1).

\section{Equilibrium solubility studies in different hydrotropic agents}

The equilibrium solubility of NVP in the presence of different hydrotropic agents was investigated as shown in Table 2. All hydrotropes, viz. lactose, urea, citric acid and mannitol, are able to enhance the solubility of NVP. The highest solubility was obtained in the $40 \%$ citric acid solution. Then, in order to decrease the concentration of citric acid, different combinations of the above-mentioned four hydrotropic agents in different ratios were tried to determine the enhancement in solubility, so that the total concentration of hydrotropic agents was always $40 \% \mathrm{w} / \mathrm{v}$. All the hydrotrope blends were also found to increase the solubility of NVP (Table 3 ). The blend P + R (lactose: citric acid) at a ratio of $5: 35$ gave the highest solubility enhancement, but the concentration of citric acid in this blend is not within the inactive ingredients guidelines (IIG) limit for a single tablet (500 mg/tablet), ${ }^{17,35}$ so the ratio of $15: 25$ was chosen, and therefore, this optimized combination of hydrotropes was selected for the preparation of solid dispersion (Table 4).

\section{Micromeritic properties of solid dispersions}

The closeness of values of tapping density and bulk density indicates the free-flowing property (Table 5). The difference in bulk density and tapped density was only 0.092 , indicating that the change in volume is very small even after 50 tappings, which confirms the small particle size

Table 2. Equilibrium solubility* of NVP in different hydrotropic agents. The data presents mean $\pm S D, n=3$

\begin{tabular}{|l|c|c|c|c|}
\hline \multirow{2}{*}{$\begin{array}{c}\text { Hydrotropic } \\
\text { Agents }\end{array}$} & \multicolumn{4}{|c|}{ Concentration (w/v) } \\
\cline { 2 - 5 } Lactose (P) & $10 \%$ & $20 \%$ & $30 \%$ & $1.13 \pm 0.126$ \\
Urea (Q) & $1.07 \pm 0.121^{*}$ & $1.09 \pm 0.101$ & $1.09 \pm 0.111$ & $11.36 \pm 1.62$ \\
Citric acid (R) & $1.39 \pm 0.152$ & $1.80 \pm 0.094$ & $2.34 \pm 0.121$ & $2.74 \pm 0.125$ \\
Mannitol (S) & $2.57 \pm 0.180$ & $3.80 \pm 0.122$ & $4.70 \pm 0.054$ & $4.18 \pm 0.123$ \\
\hline
\end{tabular}

* Solubility in mg/mL; P - lactose; Q - urea; R - citric acid; S - mannitol. 

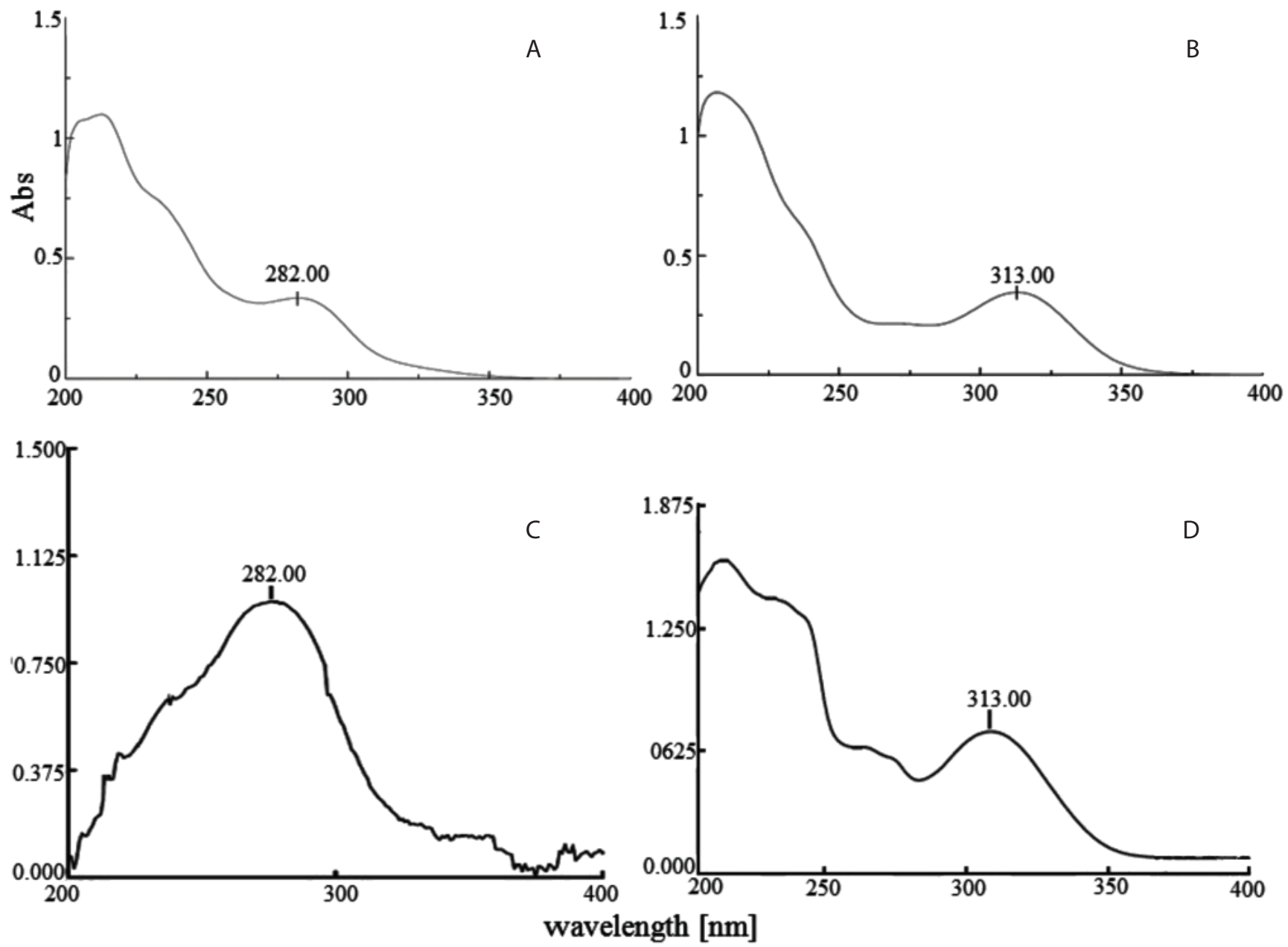

Fig. 1. UV spectra of pure NVP in (A) distilled water, (B) $0.1 \mathrm{~N} \mathrm{HCl,} \mathrm{(C)} \mathrm{NVP} \mathrm{hydrotropic} \mathrm{solid} \mathrm{dispersion} \mathrm{(lactose-citric} \mathrm{acid)} \mathrm{in} \mathrm{distilled} \mathrm{water} \mathrm{and} \mathrm{(D)} \mathrm{NVP} \mathrm{hydrotropic}$ solid dispersion (lactose-citric acid) in $0.1 \mathrm{~N} \mathrm{HCl}$

range and reproducibility in drug content. ${ }^{27,36}$ It is frequently experienced that particle size and shape influences flowability. The fine particles $(<100 \mathrm{~mm})$ tend to be more cohesive and therefore less free-flowing, whereas larger, denser particles tend to be free-flowing. The rougher and more irregular the surface of the particles, the higher the angle of repose will be. ${ }^{22}$ In the present study, the angle of repose was $33^{\circ}$, indicating good flowability of particles. A high compressibility index is indicative of the tendency to form bridges between the particles. The smaller the compressibility index, the better the flow properties will be. For example, a value of 5-15 indicates excellent flow, 12-18 good, $19-21$ fair, $22-35$ poor, $36-40$ very poor and $>40$ extremely poor. ${ }^{22}$ The results show that the solid dispersion powder had a compressibility index of 11.429 , indicating excellent flow property. Hausner ratio is related to inter-particle friction. It is also an indirect measure of bulk density, size and shape, surface area, moisture content and

Table 3. Results of equilibrium solubility of NVP in 1:1 mixed hydrotropic blends. The data presents mean $\pm S D, n=3$

\begin{tabular}{|c|c|c|c|c|}
\hline Combinations & Total conc. [\% w/v] & Individual conc. [\% w/v] & Solubility [mg/mL] & Solubility enhancement ratio \\
\hline$P+Q$ & 40.00 & 20.00 & $2.950 \pm 0.101$ & $29.67 \pm 2.51$ \\
\hline$P+R$ & 40.00 & 20.00 & $6.372 \pm 0.212$ & $64.07 \pm 1.64$ \\
\hline$P+S$ & 40.00 & 20.00 & $3.083 \pm 0.052$ & $31.01 \pm 2.09$ \\
\hline$Q+R$ & 40.00 & 20.00 & $2.640 \pm 0.184$ & $26.55 \pm 1.54$ \\
\hline$Q+S$ & 40.00 & 20.00 & $2.907 \pm 0.152$ & $29.04 \pm 2.18$ \\
\hline$R+S$ & 40.00 & 20.00 & $2.945 \pm 0.098$ & $29.62 \pm 1.72$ \\
\hline$P+Q+R$ & 40.00 & 13.33 & $1.1967 \pm 0.954$ & $12.03 \pm 1.08$ \\
\hline$P+Q+S$ & 40.00 & 13.33 & $1.4551 \pm 0.574$ & $14.63 \pm 0.81$ \\
\hline$P+R+S$ & 40.00 & 13.33 & $1.4776 \pm 0.854$ & $14.86 \pm 1.25$ \\
\hline$Q+R+S$ & 40.00 & 13.33 & $1.9677 \pm 0.799$ & $19.79 \pm 2.04$ \\
\hline
\end{tabular}

P - lactose; Q - urea; R - citric acid; S - mannitol. 
Table 4. Equilibrium solubility of NVP in mixed hydrotropic blends at different ratios. The data presents mean $\pm S D, n=3$

\begin{tabular}{|l|c|c|c|}
\hline Combinations & Total conc. $[\%$ w/v] & Ratio & Solubility [mg/mL] \\
$P+R$ & 40.00 & $05: 35$ & $10.654 \pm 0.854$ \\
$P+R$ & 40.00 & $10: 30$ & $10.022 \pm 0.965$ \\
$P+R$ & 40.00 & $15: 25$ & $10.174 \pm 0.745$ \\
$P+R$ & 40.00 & $20: 20$ & $07.761 \pm 0.854$ \\
$P+R$ & 40.00 & $25: 15$ & $05.777 \pm 0.261$ \\
$P+R$ & 40.00 & $30: 10$ & $05.258 \pm 0.350$ \\
$P+R$ & 40.00 & $35: 05$ & $02.101 \pm 0.480$ \\
\hline
\end{tabular}

P - lactose; Q - urea; R - citric acid; S - mannitol.
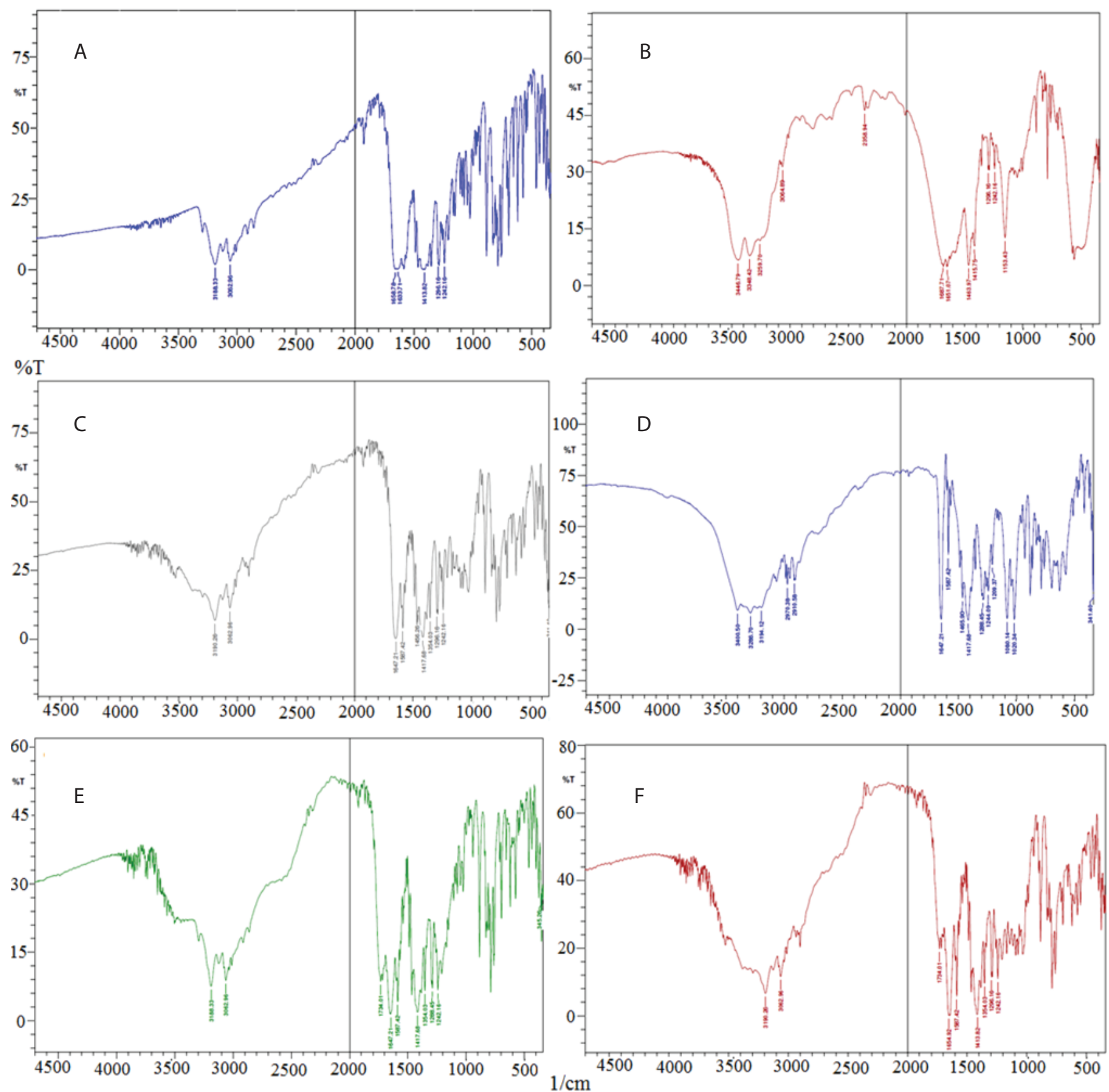

Fig. 2. Fourier transform-infrared spectra of (A) NVP, (B) nevirapine + urea, (C) nevirapine + lactose, (D) nevirapine + mannitol, (E) nevirapine + citric acid and (F) NVP + citric acid + lactose 
Table 5. Micromeritic properties of NVP solid dispersions. The data presents mean $\pm \mathrm{SD}, \mathrm{n}=3$

\begin{tabular}{|l|c|}
\hline \multicolumn{1}{|c|}{ Parameter } & Result \\
\hline Bulk density $\left(\mathrm{g} / \mathrm{cm}^{3}\right)$ & $0.714 \pm 0.01$ \\
Tapped density $\left(\mathrm{g} / \mathrm{cm}^{3}\right)$ & $0.806 \pm 0.03$ \\
Compressibility index & $11.429 \pm 2.31$ \\
Hausner ratio & $1.12 \pm 0.14$ \\
Angle of repose & $33 \pm 1^{\circ}$ \\
\hline
\end{tabular}

cohesiveness of particles. A higher Hausner ratio and more fine particles indicate greater cohesion between particles while a low range indicates good flowability. The desirable value of Hausner ratio is $<1.25$ for good flow of materials. $^{22}$ In the present study, the Hausner ratio for the solid dispersion powder was found to be 1.12 indicating good flowability of particles. This result was also supported by an angle of repose study. These results indicate that the flow character of the solid dispersion is good and no aid is needed to increase the flow properties.

\section{X-ray diffraction analysis of NVP}

It is generally stated that if three consecutive relative intensity percentage values in an XRD pattern decrease, a decrease in crystallinity had occurred in the samples, therefore, these observations can be treated as confirmation of the reduction in crystallinity and thus phase transition. ${ }^{37}$ As it is reported that an amorphous system is responsible for the enhancement in dissolution and bioavailability, ${ }^{38}$ less intense peaks in the solid dispersion as

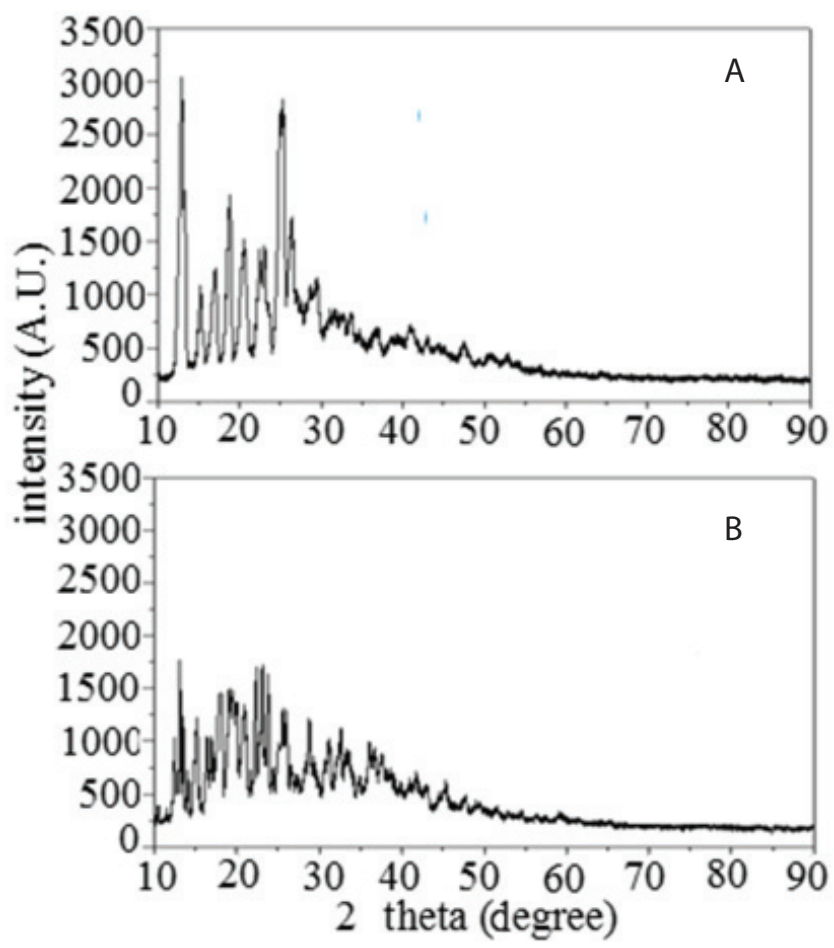

Fig. 3. X-ray powder diffraction spectra of (A) NVP and (B) NVP hydrotropic solid dispersion (lactose-citric acid)
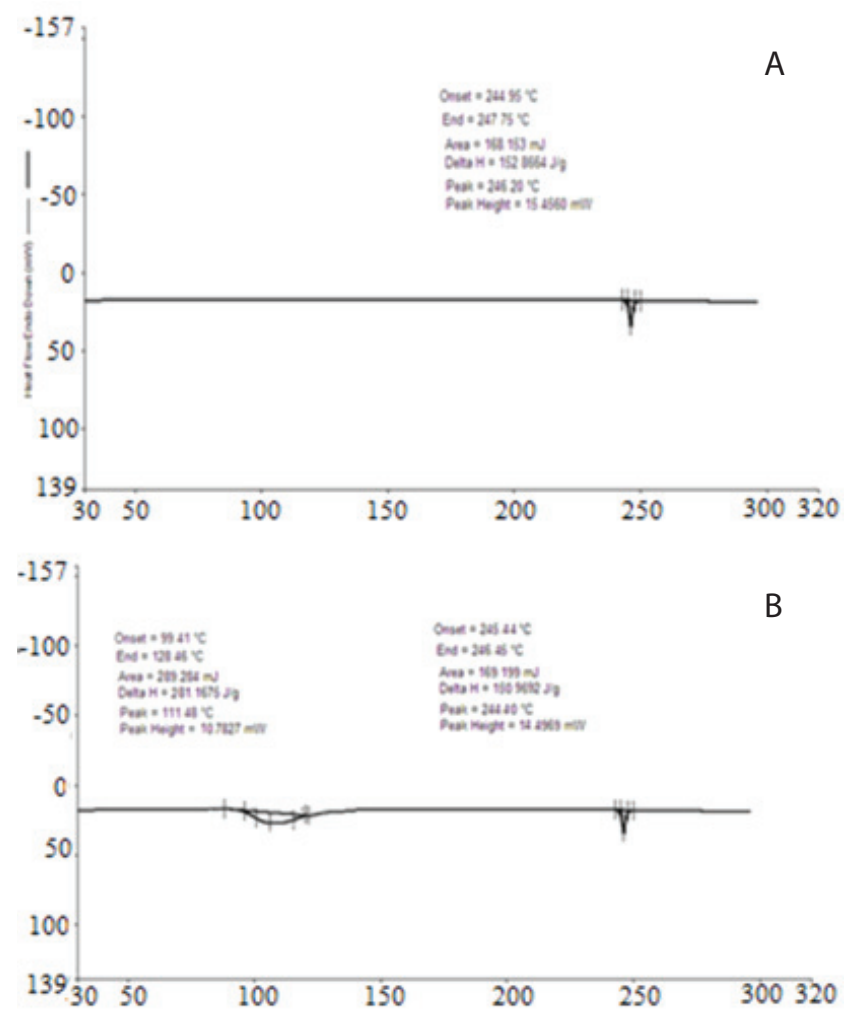

Fig. 4. Differential scanning calorimetry thermogram of (A) NVP and (B) NVP hydrotropic solid dispersion (lactose-citric acid)

compared to the NVP pure drug indicate an amorphous nature, explaining the higher solubility of SD as compared to NVP (Fig. 2). These observations were in accordance with the DSC studies (Fig. 3).

\section{Differential scanning calorimetry analysis}

The DSC thermogram of NVP is shown in Fig. 3a. The DSC thermogram of NVP shows an endothermic melting peak at $246.20^{\circ} \mathrm{C}$, indicating its melting point $\left(244-247^{\circ} \mathrm{C}\right)$. The DSC thermogram of NVP solid dispersion is shown in Fig. 3b. There was no shift in the NVP endothermic peak; hence there was no NVP and excipient (lactosecitric acid) interaction. The separate endothermic peak of lactose was found at $111.4^{\circ} \mathrm{C}$ due to its dehydration. ${ }^{39}$

\section{Conclusion}

From the present research, we conclude that hydrotropy is an effective, safe and novel method to increase the solubility of poorly water-soluble drugs. Quick dissolution of the practically insoluble drug NVP in aqueous dissolution media indicates its potential to solubilize the drug in biological fluids, and thus significant enhancements in the onset of the effect and bioavailability can be seen. Therefore, the concept of mixed hydrotropy is an emerging field and greater importance must be given by the scientific community to explore its applicability and efficiency. 


\section{References}

1. Dua K, Ramana MV, Sara UV, et al. Investigation of enhancement of solubility of norfloxacin beta-cyclodextrin in presence of acidic solubilizing additives. Curr Drug Deliv. 2007;4(1):21-25.

2. Gorajana A, Rajendran A, Yew LM, Dua K. Preparation and characterization of cefuroxime axetil solid dispersions using hydrophilic carriers. Int J Pharm Investig. 2015; 5:171-178.

3. Kumar N, Jain AK, Singh C, Agarwal K, Nema RK. Development, characterization and solubility study of solid dispersion of terbinafine hydrochloride. Int J Pharm Sci Nanotech. 2008;1:171-176.

4. James K. Solubility and related properties. Vol. 28, Marcel Dekker, New York, 1986, 127-146, 355-395.

5. Aulton ME. Pharmaceutics - The Science of Dosage Form Design. $2^{\text {nd }}$ Ed, Harcourt Publishers Limited; 2002.

6. Waterbeemed HVD, Testa B. Drug bioavaibility; estimation of solubility, permeability, absorption. Wiley Online Library. 2009.

7. United State Pharmacopoeia XXI - NF XVI. Rockville, MD: United States Pharmacopeial Convention; 1985:1336.

8. Aggarwal S, Gupta GD, Chaudhary S. Solid dispersion as an eminent strategic approach in solubility enhancement of poorly soluble drugs. Int J Pharma Sci Res. 2010;1:1-13.

9. Bauduin P, Renoncourt A, Kopf A, Touraud D, Kunz W. Unified concept of solubilization in water by hydrotropes and co solvents. Langmuir. 2005;21:6769-6775.

10. Dhapte V, Mehta P. Advances in hydrotropic solutions: An updated review. St. Petersburg Polytechnic Univ J Phys Math. 2015;1:424-435.

11. Madan JR, Pawar KT, Dua K. Solubility enhancement studies on lurasidone hydrochloride using mixed hydrotropy. Int J Pharm Invest. 2015;5:114-120.

12. Kumar A, Sahoo AK, Padhee K, Pal P, Singh K. Review on Solubility Enhancement Techniques for Hydrophobic Drugs. Int J Comprehensive Pharm. 2011;3(3):1-7.

13. Elder DP, Holm R, Diego HL. Use of Pharmaceutical Salts and Cocrystals to Address the Issue of Poor Solubility. Int J Pharm. 2013;453:88-100.

14. Miyako Y, Khalef N, Matsuzaki K, Pinal R. Solubility enhancement of hydrophobic compounds by cosolvents: Role of solute hydrophobicity on the solubilization effect. Int J Pharm. 2010;393:48-54.

15. Kim J, Kim S, Papp M, Park K, Pinal R. Hydrotropic solubilization of poorly water soluble drugs. J Pharm Sci. 2010;9:53-65.

16. Pawar AR, Choudhari PD. Novel techniques for solubility, dissolution rate and bioavailability enhancement of class II and IV drugs. Asian J Biomed Pharma Sci. 2012;13(2):9-14.

17. Kumar A, Sahoo AK, Padhee K, Pal P, Singh K. Review on solubility enhancement techniques for hydrophobic drugs. Int J Comprehensive Pharm. 2011;3(3):1-7.

18. Limbachiya MI, Agarwal M, Sapariya A, Soni S. Solubility enhancement techniques for poorly soluble drugs: Review. Int J Pharm Res Develop. 2011;4(4):71-86.

19. Jatwani S, Rana AC, Singh G, Aggarwal G. An overview on solubility enhancement techniques for poorly soluble drugs and solid dispersion as an eminent strategic approach. Int J Pharm Sci Res. 2012;3(4):942-956.

20. Sikarra D, Shukla V, Kharia AA, Chatterjee DP. Techniques for solubility enhancement of poorly soluble drugs: An overview. J Med Pharm Allied Sci. 2012;1:1-22.

21. Gorajana A, Kit WW, Dua K. Characterization and solubility study of norfloxacin-polyethylene glycol, polyvinylpyrrolidone and carbopol 974P solid dispersions. Recent Pat Drug Deliv Formul. 2015;9(2):167-182.

22. Behera AL, Sahoo SK, Patil SV. Enhancement of solubility: A pharmaceutical overview. Der Pharmacia Lettre. 2010;2(2):310-318.

23. Saleh AM, El-Khordagui LK. Hydrotropic agents: A new definition. Int J Pharm. 1985;24:231-238.

24. Yalkowsky SH. Solubility and solubilization in aqueous media. New York, NY: Oxford University Press; 1999.

25. Leuenberger $\mathrm{H}$. Spray freeze-drying - the process of choice for low water soluble drugs? J Nanopart Res. 2002;4:111-119.

26. Madan JR, Kamate VJ, Awasthi R, Dua K. Formulation, characterization and in-vitro evaluation of fast dissolving tablets containing gliclazide hydrotropic solid dispersions. Recent Pat Drug Deliv Formul. 2017; [E-pub ahead of print].
27. Awasthi R, Kulkarni GT. Development and characterization of amoxicillin loaded floating microballoons for the treatment of Helicobacter pylori induced gastric ulcer. Asian J Pharm Sci. 2013;8:174-180.

28. Dhiman N, Awasthi R, Jindal S, Khatri S, Dua K. Development of bilayer tablets with modified release of selected incompatible drugs. Polim Med. 2016;46(1):5-15.

29. Das P, Kumar K, Nambiraj A, Awasthi R, Dua K, Himaja M. Potential therapeutic activity of Phlogacanthus thyrsiformis Hardow (Mabb) flower extract and its biofabricated silver nanoparticles against chemically induced urolithiasis in male Wistar rats. Int J Biol Macromol. 2017;103:621-629.

30. Ramana MV, Dua K, Awasthi R. Development and characterization of solid dispersion-microsphere controlled release system for poorly water soluble drug. Drug Deliv Trans Res. 2016;6(5):540-550.

31. Lyn LY, Sze HW, Rajendran A, Adinarayana G, Dua K, Garg S. Crystal modifications and dissolution rate of piroxicam. Acta Pharm. 2011;61:391-402.

32. Dua K, Pabreja K, Ramana MV, Lather V. Dissolution behavior of $\beta$-cyclodextrin molecular inclusion complexes of aceclofenac. J Pharm Bioallied Sci. 2011;3(3):417-425.

33. RamkumaarGR, Srinivasan S, BhoopathyTJ,Gunasekaran S, Charles J, Ramesh J. Molecular structure, vibrational spectra, UV-vis, NBO, and NMR analyses on nevirapine using ab initio DFT methods. J Theor Appl Phy. 2013;7:51.

34. Sarkar M, Perumal OP, Panchagnula R. Solid-state characterization of nevirapine. Ind J Pharm Sci. 2008;70(5):619-630.

35. Inactive ingredient search for approved drug products. https:// www.accessdata.fda.gov/scripts/cder/iig/getiigWEB.cfm. Published June 4, 2017. Updated July 5, 2017. Accessed July 20, 2017.

36. Maheshwari RK, Jagwani Y. Mixed Hydrotropy: Novel Science of Solubility Enhancement. Indian J Pharm Sci. 2011;73(2):179-183.

37. Zidan AS, Rahman Z, Sayeed V, Raw A, Yu L, Khan MA. Crystallinity evaluation of tacrolimus solid dispersions by chemometric analysis. Int J Pharm. 2012;23:341-350.

38. Newman A, Knipp G, Zografi G. Assessing the performance of amorphous solid dispersions. J Pharm Sci. 2012;101:1355-1377.

39. Raut DM, Allada R, Pavan KV. Dehydration of Lactose Monohydrate: Analytical and Physical Characterization. Der Pharmacia Lettre. 2011;3(5):202-212. 